\title{
Sağlık Hizmetlerinde Çalışan Güvenliği
}

\author{
Employee Safety in Health Services
}

\author{
Asu GÜRER
}

ÖZ

Sağlık çalışanları yaptıkları işin özelliklerine göre farklı iş riskleriyle karşı karşıya kalmaktadırlar. Bu riskler arasında enfekte iğne ile yaralanmalar, ilaç alerjileri, radyasyon, kronik hastalıklar, çeşitli psikososyal sorunlar yer alır. Bu durumda çalışanın iş performansı azalmakta, iş kazaları artmakta, hem çalışan hem de hasta için güvenlik sorunları ortaya çıkmaktadır. Ülkemizde, sağlık çalışanının sağlığına ve güvenliğine ait "Hasta ve Çalışan Güvenliğinin Sağlanmasına Dair Yönetmelik" adlı düzenleme ile, hastanelerde çalışan sağlığ1 ve güvenliği komitelerinin kurulması, sağlık çalışanına bu konuda gerekli eğitimin verilmesi, çalışanın sağlık taramalarının belirli aralıklarla yapılması, koruyucu önlemlerin alınması, sağlıkta şiddeti önlemek adına çeşitli girişimler yürütülmektedir. $\mathrm{Bu}$ makalede çalışan güvenliğinin önemi vurgulanmış, sağlık çalışanlarının karşılaşabileceği riskler ve alınabilecek önlemlere değinilmiştir. Bu konuda farkındalığın artırılması, güvenli çalışmanın kurum kültürü haline getirilmesi gerektiği düşünülmektedir.

Anahtar Kelimeler: İş, sağlık, çalışan güvenliği, sağlık çalışanı

\begin{abstract}
Healthcare professionals are exposed to different business risks according to the characteristics of the job they are doing. These risks include injuries with infected needles, drug allergies, radiation, chronic illnesses, various psychosocial problems. In this case, the work performance of the employee decreases, the work accidents increase, safety problems occur for both the employee and the patient. In our country, establishment of health and safety committees working in hospitals, providing the necessary training to the healthcare workers, carrying out employee health checks at certain intervals, taking preventive measures, preventing health violence in health services is provided with "Regulation on the Ensuring Patient and Employee Safety" entitled regulation. This article emphasizes the importance of employee safety, addressed the precautions and risks faced by healthcare workers. It is thought that raising awareness on this issue and safe working needs to be brought into the corporate culture.
\end{abstract}

Keywords: Profession, health, employee safety, healthcare professionals

\section{GíRiș}

Sağlık terimi farklı şekillerde tanımlanabilmesine rağmen kabul gören ve evrensel bir tanım olarak karşımıza çıkan sağlık tanımını Dünya Sağlık Örgütü'nün (DSÖWHO) kuruluş anayasasında kullandığı sağlık tanımıdır. 1948'deki bu tanıma göre sağlık yalnızca hastalık veya sakatlık durumunun olmayışı değil, bedensel, ruhsal ve sosyal açıdan tam bir iyilik halidir (1). Bu iyilik halinin olmayışı ise hastalık olarak belirtilir. Sağlık hizmetleri ise kişilerin sağlığını korumak, hastalıkların tanı, tedavi ve bakımlarını kişisel ve kurumsal olarak yapabilmek için, kamu kurumlarının ya da özel sağlık kuruluşlarının verdiği hizmetler olarak tanımlanır (2). Sağlık çalışanları olarak ifade edilen kişiler, hastalara veya doku parçalarına, enfekte
Asu GÜRER ( $\bowtie)$

Marmara Üniversitesi Sağllk Hizmetleri Meslek Yüksekokulu,Anestezi Programı

D-100 Güney Yanyolu Üzeri, Cevizli Mahallesi, 34865 Kartal/ ISTANBUL e-posta: asu.gurer@marmara.edu.tr 
tıbbi malzemelere, hava da dahil olmak üzere, temas etme potansiyeli olan, sağlık bakım birimlerinde çalışan ücretli ve ücretsiz kişilerdir (3). Sağlik hizmetlerinin güvenli, etkili ve kaliteli sunulması, sağlık çalışanlarının kapasitesi ve hizmet sunumunda mükemmelliği destekleyen çalışma ortamına bağlı olmakla birlikte sağlık çalışanlarının sağlığ 1 çoğu zaman ihmal edilmiştir $(4,5)$.

Sağlık kurumları, çalışma koşulları bakımından çok riskli gruba giren kurumlardır. Sağlık çalışanları bir yandan işlerinin gereğini yaparken, aynı zamanda ciddi iş kazaları yaşayabilmekte ya da meslek hastalıkları geçirebilmektedirler. Olası tehlikeleri ve meydana gelebilecek riskleri en aza indirilebilmek için sağlık kurumlarında Akreditasyon standartlarına uyulması, kalite yönetim sistemlerinin uygulanması, olası kaza ve hastalıkların en aza inmesinde etkili olacaktır. Ülkemizde Sağlık Bakanlığı tarafindan yayınlanan ve sağlık kuruluşlarında uygulamanın zorunlu tutulduğu Sağlık Hizmet Kalite Standartları (SHKS) kaliteyi gerçekleştirme adına çalışan güvenliğini de dikkate alarak sağlık hizmeti sunumuna yeni bir bakış açısı getirmiştir (6). Ayrıca üniversite ve özel sektör ikinci ve üçüncü basamak sağlık kurumlarını kapsayan "Hasta ve Çalışan Güvenliğinin Sağlanmasına Dair Yönetmelik" ile sağlık kurumlarında, hem hasta hem çalışanların güvenliği için güvenli hizmet sunumu ve güvenli bir ortam sağlanmasına, hizmet sunumunu gerçekleştirirken kalitenin artırılmasına, sağlık kurumunda hasta ve çalışanlar için muhtemel risklerin saptanmasına, bu risklerin giderilmesi için uygun tekniklerin belirlenmesine ve hizmet içi eğitimlerin yapılması ile güvenli hizmet sunumu ve güvenli çalışma ortamının sürdürülebilirliğinin sağlanmasına yönelik usul ve esaslar düzenlenmektedir.

$\mathrm{Bu}$ çalışma sağlık hizmetlerinde çalışan güvenliğinin önemi ve sağlık çalışanlarının maruz kaldıkları tehlike ve riskleri, oluşabilecek risk durumlarında yapılabilecekleri vurgulamakta, sağlıkta kalite standartları çerçevesinde çalışan güvenliğinin önemine değinmekte, çalışan güvenliği konusunda farkındalığın artmasını ve bu konuda yapılacak çalışmalara katkı sağlamayı amaçlamaktadır.

\section{ÇALIŞAN GÜVENLİĞI}

DSÖ, "çalışan bireylerin fiziksel, ruhsal ve sosyal durumunun üst düzeye çıkartılması, çalışanın sağlığında meydanagelebilecekrisklerinenazaindirilmesiiçinkoruyucu önlemlerin alınması ve uygulanması, çalışanın işine, işin çalışana uygun olması" şeklinde çalışan güvenliği tanımını yapmıştır. Sağlık çalışanlarının çalışma ortamlarındaki tehlikeler çalışanın güvenliğini tehlikeye sokmakla birlikte hastanelerde hataların oluşmasına da neden olmakta, bu durum ise hem hasta güvenliğini tehlikeye sokmakta hem de hastaların tedavilerini olumsuz yönde etkilemektedir. $\mathrm{Bu}$ durumda sağlık çalışanının tehlikelerden uzak tutulması aslında hastanın da tehlikelerden uzak tutulması anlamına gelmektedir. Bu sebeplerle çalışma ortamını olası tehlike ve risk oluşumu açısından değerlendirmek önemlidir. $\mathrm{Bu}$ değerlendirmelerle, olası tehlikeler ortaya çıarılmakta ve bertaraf edilmekte, çalışanların kendilerinin göremediği problemler belirlenmekte ve yapılan kontrollerin etkinliği $\operatorname{artmaktadır}(7,8)$.

Öztürk ve arkadaşlarının yaptığı çalışmada aktardığ1 gibi, Amerika Birleşik Devletleri Ulusal İş Sağllğı ve Güvenliği Kurumu (National Institute for Occupational Safety and Health= NIOSH), sağllkl1, verimli, etkin ve güvenilir hastane ortamını "işin yapılması sırasında oluşan ve sağlık için zararlı olan fiziksel, kimyasal, biyolojik, ergonomik olmak üzere her türlü tehlikeler ve bu tehlikelerin neden olabileceği risklere bağlı olarak ortaya çıkan iş kazası ve meslek hastalıklarının gerçekleşmemesi hali” şeklinde ifade etmiştir (9). Ancak sağlık alanında çalışanlar kontaminasyon, toksik ilaçlar, kullanılan malzemelerden kaynaklanan ergonomik sorunlar, enfekte tıbbi atıklar, malzeme eksikliği, iş yükünün fazla olması, çalışma ortamında dikkatsiz davranışlar gibi sebeplerle çeşitli sorunlar yaşayabilmekte ve bunların sonucunda da çeşitli hastalık riskleri ile karşı karşıya kalabilmektedirler.

Sağlık hizmetlerinin kalitesini ve güvenliğini arttırmaya odaklanmış, kar amacı gütmeyen Joint Commission On Accreditation Of Healthcare Organizations (JCAHO) kurumunun uluslararası akreditasyon hizmetleri için oluşturulmuş birimi olan Joint Commision International (JCI) ve Sağlık Bakanlığı'nın sunduğu hizmet kalite standartları, hasta ve çalışan güvenliğine işaret eden yönetmelik ile hasta güvenliğini sağlamanın yanında çalışan güvenliğinin sağlanmasına ait kriterlere de yer vermiş, konunun önemi vurgulanmış, yapılan düzenlemelerle sağlık alanında çalışanın iş güvenliği güvenceye alınmaya başlamıştır $(10,11)$.

\section{SAĞLIK ÇALIŞANLARININ MARUZ KALDIĞI TEHLIKE VE RİSKLER}

NIOSH, çalışma ortamında oluşan tehlike ve riskleri fiziksel, kimyasal, biyolojik, ergonomik ve psikososyal tehlike ve 
riskler olarak sınıflandırmış ve hastanelerde 29 tip fiziksel, 25 tip kimyasal, 24 tip biyolojik, 6 tip ergonomik ve 10 tip psikososyal tehlike ve risk olduğunu tespit etmiştir $(12,13)$.

\section{1- Fiziksel Tehlike ve Riskler}

Kanserojen, teratojen ve mutajen etkileri olan iyonizan ve non-iyonizan radyasyon riskleri, ultraviyole ışılnarı, laser, ultrason cihazları, bilgisayar ekranları, aydınlatma koşullarının yarattığı sorunlar, havalandırma sistemleri, gürültüye bağlı ortaya çıkabilecek sorunlar, çalışma ortamının hava kirliliği sorunları sağlık çalışanlarını olumsuz etkilemektedir (14).

DSÖ, çalışma ortamındaki gürültünün gündüz 40 Desibel (dB), gece $35 \mathrm{~dB}$ seviyesinde olmasını önerir. Hastaların yattıkları bölümde bu düzey $35-40$ dB'i aşmamalıdır. Ses düzeyleri aşıldığında çalışan sağlığının olumsuz etkilenmesiyle birlikte çalışanın iş verimi de düşer. Fakat hastanelerin birçok biriminde ses düzeyi 51Db-90 dB civarında olabilmektedir.

Sıcaklık, fiziksel tehlike ve riskler açısından önemli bir yerdedir. Yoğun bakım ünitelerinin sıcaklığının $24-27{ }^{\circ} \mathrm{C}$, hastaların bulunduğu odaların $22-24{ }^{\circ} \mathrm{C}$, ameliyathanelerin sıcaklığının $20-22{ }^{\circ} \mathrm{C}$ olması kabul edilir. Havalandırma sistemlerinin, havayı filtre edebilmesi, uygun 1sıy1 ve nemi sağlayabilmesi gereklidir. Hastanelerde havalandırma sistemlerinin istenilen özelliklerde olması, filtre edebilme işlemlerini yapabilmesi çalışanların özellikle solunum yoluyla geçen enfeksiyonlardan koruması için önemlidir. Ameliyathaneler steril ortamlar olduğundan buralarda enfeksiyon riski en alt seviyede ve mikroorganizma yoğunluğu standartlar çerçevesinde tutulmalı, bunun için de hastanelere özel havalandırma sistemleri kurulmalıdır (13).

Fiziksel risklere karşı alınabilecek önlemler ve yapılabilecekler arasında;

- çalışılan alanın zemininin su, kan veya diğer sıvılar nedeniyle kaygan olmasını önleyecek malzemeden yapılması,

- zeminin 1slak bırakılmaması,

- kullanılan cihaz ve kabloların takılmalara neden olmayacak şekilde yerleştirilmesinin sağlanması,

- radyasyondan korunmak için uygun malzemelerin kullanımının sağlanması,

- çalışanın radyasyona maruziyetinin takibinin yapılması,

- ortam havalandirması,
- gürültüye maruziyete sebep olan cihazların tespit edilip önlem alınması,

- çalışılan ortam için en uygun 1 şık ve havalanma sistemlerinin seçilmesi sayılabilir.

\section{2- Kimyasal Tehlike ve Riskler}

Hastane laboratuvarlarında kullanılan asit ve alkali maddeler, boyalar, uçucu organik çözücüler, hasta tedavisinde kullanılan (kanser ilaçları gibi) çeşitli ilaçlar, sterilizasyon ve dezenfeksiyon amacı ile kullanılan çeşitli kimyasal ajanlar, formaldehit, glutaraldehit, etilen oksit gibi maddeler çalışanlar için alerji oluşumundan kansere birçok hastalığın oluşumunda önemli risk faktörü oluşturmaktadır (14).

Kimyasal risklere karşı alınabilecek önlemler ve yapılabilecekler arasında;

- dezenfeksiyon ve sterilizasyon amaçlı kullanılan kimyasallar için kolay anlaşılan bilgi ve kullanım talimatlarının hazırlanması,

- bu maddelerin kulanımına ilişkin uygulamalı eğitimlerin verilmesi,

- lateks alerjisine karşı çalışanların takip edilip uygun malzemenin temininin ve kullanımının sağlanması,

- kimyasal ilaçların kullanımı sonrası çalışanların gözlemlenmesi ve gerektiğinde tetkiklerin yapılması,

- oluşan alerji durumlarında çalışanların bu durumunun takibinin uygun şekilde yapılmasının sağlanması ve kayıtların tutulması,

- zararlı kimyasallar ve gazlar hakkında verilen eğitimin ardından eğitimlerin belirli aralıklarla tekrarlarının sağlanması,

- eğitimin etkinliğinin ölçülmesi sayılabilir.

\section{3- Biyolojik Tehlike ve Riskler}

Biyolojik tehlike ve riskler çalışma alanının hepsinde görülmekte, sağlık çalışanlarında kan veya kanla kontamine olmuş vücut sıvilarıyla temas ile HIV (Human Immunodeficiency Virus), Hepatit B (HBV), Hepatit C (HCV) gibi ciddi sağlık sorunlarının yaşanmasına neden olabilmekte, tüberküloz ve diğer çeşitli enfeksiyon hastalıklarının görülmesi sıklığı artabilmektedir $(15,16,17,18)$. 
Kesici alet yaralanmalarını önleme çalışma kitabında belirtildiğine göre; sağlık alanında kullanılan kesicidelici aletler belirtilmiş ve sağlık çalışanlarında 5 yıllık bir dönemde 5000 perkütan yaralanma olduğu belirlenmiş ve bu vakaların \%62'sinin iğne batması ile gerçekleştiği, bunlarla yaralanmaların \%38'inin perkütan aletlerin kullanımı esnasında, \%42'sinin tek kullanımlık olan aletlerin kullanım öncesi ve bu aletleri kullandıktan sonra gerçekleştiği tespit edilmiştir (19). Ankara'da yürütülen başka bir çalışmada üçüncü basamak bir sağlık kuruluşunda çalışan doktor, hemşire, laboratuvar teknisyeni, radyoloji teknisyeni ve güvenlik görevlisi gibi çeşitli görevlerde çalışan 491 hastane çalışanında tüberküloz enfeksiyonu riskinin varlığ araştırılmış ve PPD pozitifliğinin $\% 83$ olduğu bulgusuna ulaşılmıştır (20).

Biyolojik risklere karşı alınabilecek önlemler ve yapilabilecekler arasinda;

- biyolojik ajanlara karşı denetimin, kontrolün yapılması,

- çalışan personele aşılamanın periyodik uygulanması,

- gerekli takiplerin yapılması,

- kan ve her türlü vücut sıvısı ile bulaşmaya karşı kişisel koruyucu donanımların mutlaka kullanılmasının sağlanmas1,

- bulaşma olduğunda ise uygun tedavinin yapılması ve takip sistemi ile mutlaka izlenmesi,

- gerekli kayıtların tutulması,

- çalı̧̧an güvenliği için gerekli olan, kesici-delici alet yaralanmaları ve iğne batmalarını önleyen kilit/emniyet sistemleri olan ürünlerin kullanılması,

- özel vakalarda koruyucu giysi ve ekipman kullanımının sağlanmas1,

- tıbbi atıklar için atık kaplarının kullanımının sağlanması ve atıkların uygun şekilde bertarafının yapılması,

- bu konuda çalışanlara gerekli eğitimin verilmesi sayılabilir.

\section{4- Psikososyal Tehlike ve Riskler}

Psikososyal sorunların ortaya çıkmasındaki en önemli sebepler arasında çalışma sürelerinin uzun olması, sağlık çalışanının gece de çalışmasının devam etmesi ve tutulan nöbet sayısının fazla olması gelmektedir (21). Bu durumda çok sayıda sağlık sorunu ve iş güvenliği problemleri ortaya çıkabilmektedir. Bunların başlıcaları yorgunluk, uykusuzluk ve bunlara bağlı gelişen kazalar, hafıza problemleri, yapılan işe yoğunlaşmada sorunlar, problemleri çözememe, yaralama ve yaralanmalar, malpraktis ile karşılaşılması, kanser gibi ciddi hastalıklar yanında kronik hastalıkların da ortaya çıkması, duygu-durum bozukluğu, tükenmişlik sendromu, kendini ait hissedememe gibi sorunların yanında çalışanlar aile içi sorunlar da yaşayabilmektedirler $(22,23,24)$.

Psikososyal risklere karşı alınabilecek önlemler ve yapılabilecekler arasinda;

- stres yönetimi için çalışanın desteklenmesi, takip edilmesi ve bu konuda eğitim verilmesi, uykusuzluk, yorgunluk, dikkatsizlik gibi sorunların ortaya çıkmasına neden olan uzun çalışma saatlerine karşı iş yükü dağılımlarının sistemli şekilde yapılması ve güncellenmesinin sağlanması, şiddeti önlemeye yönelik uygulanan "Beyaz Kod" gibi uygulamaların geliştirilmesi ve kapsamlı hale getirilmesi,

- tükenmişlik sendromu gibi psikolojik rahatsızlıklara karşı gerekli tetkiklerin belirli aralıklarla yapılması,

- yapılan uygulamaların kayıt altına alınması ve takip edilmesi,

- ilaç bağımlılığına karşı gerekli tedbirlerin alınması ve takibin sağlanması,

- çalışan güdülenmesi ve uyumunu sağlamak için kurum içi sosyal aktivitelerin desteklenmesi sayılabilir.

\section{5- Ergonomik Tehlike ve Riskler}

Çalışanlar hizmet sundukları alanlarda hasta kaldırma, taşıma gibi efor gerektiren işleri yaptıklarından, kullanılan tıbbi ekipmanın uygunsuz olmasından kaynaklanan nedenlerle çeşitli tehlike ve risklere maruz kalmaktadırlar. Hasta ile yakın temas gerektiren bu işleri yapmak için kullanılan uygun olmayan malzemeler nedeniyle çalışanlar sıklikla kas-iskelet sistemini ilgilendiren sorunlar yaşayabilmektedirler. Bel ağrısı, boyun, omuz ve kol ağrıları, karpal tünel sendromu bu sorunların başında yer alır $(18,25)$.

Ergonomik risklere karşı alınabilecek önlemler ve yapılabilecekler arasında;

- hasta taşıma ve uygun duruş teknikleri için uygulamalı eğitimlerin verilmesi,

- eğitimlerin düzenli olarak yapılması ve gerekli takibin sağlanması,

- kullanılan tıbbi ekipmanların ergonomik açıdan risk oluşturmayacak olanlardan seçilmesi, 
- sağlık çalışanının kas iskelet problemlerine yönelik düzenli olarak sağlık kontrollerinin yapılması,

- çalışanların gözlenmesi ve yapılan işlemlerin kayıt altına alınıp takip edilmesinin sağlanması sayılabilir.

\section{SONUÇ}

Sağlık hizmetleri, farklı uzmanlık alanlarında çalışan kişiler tarafından sunulan emeği yoğun hizmetler olup, çalışma ortamı açısından çok riskli olarak kabul edilen birimlerde hizmet verilmekte, bu hizmeti sunan sağlık çalışanları ise kesici-delici alet ile yaralanmalar, enfeksiyon hastalıkları, ergonomik tehlikelerin varlığı ve bunlara bağlı ortaya çıkabilecek kas iskelet sistemi sorunları, alerjiler, radyasyon, kronik hastalıklar, psikososyal sorunların yaşanmasına bağlı olarak gelişebilen şiddet, stres, uyum bozukluğu, dikkatsizlik gibi çalışanın hem çalışma hem de sosyal yaşamını etkileyebilecek çeşitli durumlarla karşı karşıya kalmaktadırlar. Sağlık hizmetlerinin güvenli, kaliteli, etkili ve verimli sunulması, aynı zamanda sağlık çalışanının sağlıklı ve güvenli olmasına, çalışma kapasitesine ve çalışırken sergilediği performansa da bağlı olduğundan, sağlık hizmeti sunan çalışanın sağlığı ve güvenliği konusu üzerinde özenle durulması gereken konulardandır. $\mathrm{Bu}$ konuya dikkat çekmek, farkındalık yaratmak ve gerekli önlemler konusunda öneri sunmak adına çalışmalar yapılmış ve yapilmaktadır.

Vural ve arkadaşlarının yaptığı çalışmada radyasyon güvenliği konusuna dikkat çekilmiş ve çalışmadan çıkan sonuçta, bu konuda ameliyathane çalışanlarının radyasyonun çalışan sağlığ üzerinde olumsuz sonuçlar doğurabileceğini bilmelerine rağmen koruyucu tedbirleri göz ardı ettikleri sonucuna ulaşmışlardır (26).

NIOSH 2600 hastanenin iş sağlığ 1 servislerinin raporlarını değerlendirmiş, çalışanların en çok kas iskelet sistemi sorunları yaşadıklarını saptamıştır. Ardından gelen sorunlar arasında kesici delici aletlere bağlı travmatik yaralanmalar, çizilme ve ezilmeler, yanıklar ve fraktürlerin olduğunu belirtmişlerdir. Sık görülen hastalıklar arasında ise solunum sistemi ile ilgili hastalıkların, enfeksiyon hastalıklarının, çeşitli cilt hastalıklarının ve alerjik reaksiyonların olduğu bildirilmiştir $(27,28)$.

Kanada'da yapılan çalışmada acil servis hizmeti sunulan birimlerde çalışanların şiddete uğrama oranlarının yüksek olduğu belirlenmiştir. Yürütülen çalışmada herhangi bir zamanda şiddete uğrama oranının $\% 60$, sözel şiddetin $\% 76$, fiziksel şiddetin \%86 oranında görüldügü belirtilmiştir.
Çalışmaya katılanların \%73'ü şiddete uğradıkları için hastalardan korktuklarını, \%74'ü bu sorun nedeni ile iş doyumlarının azaldığını belirtmişlerdir. Şiddete uğrayanların şiddeti raporlama oranı $\% 67$ olarak bulunmuş, şiddete uğrayanların bir kısmında da iş değişikliği yoluna gidildiği belirlenmiştir $(29,30)$.

Ülkemizde yürütülen başka bir çalışmada, bir üniversite hastanesindeki sağlık çalışanlarının tüberküloz riski incelenmiş; hastalarla yakın temas halinde çalışanlarda tüberküloz gelişme hızı; genele bakıldığında 100.000 'de 200 olduğu, bu oranın hemşirelerde 100.000 'de 274 'e çıktığı, saptanmıştır (31). Çalışmanın yürütüldüğü tarihlerde ülkemizde tüberküloz görülme olasillğının 100.000'de 40,8 olduğu belirtilmiştir. $\mathrm{Bu}$ durumda sağlik hizmeti sunan personellerde, özellikle de hemşire olarak çalışanlarda tüberküloz gelişme hızının oldukça yüksek olduğunu söylemek mümkündür (32). Hoşoğlu ve arkadaşlarının yürüttüğü çalışmada hemşirelerin ardından, yardımcı sağlık personelinin büyük risk altında olduğu, daha sonra ise doktorların tüberküloz gelişme riski ile karşı karşıya kaldıkları rapor edilmiştir.

Var olan yasal düzenlemeler ve sağlıkta kalite standartları çerçevesinde sağlık çalışanlarına iş sağlı̆̆ ve güvenliği (ISG) eğitiminin verilmesi, verilen eğitimin ardından ölçme-değerlendirme yapılması zorunluluğu vardır (33). Çalışanların aldıkları eğitimlerin, çalışanların İSG düzeylerinin artırılmasına olan etki ve katkısının incelenmesi gerekmektedir. Sağlık kurumu çalışanları, beklentilerin yüksek olduğu ve özverili çalışmayı gerektiren çalışma grubunu ifade etmektedir. Sağlık çalışanının ürettiği sağlık hizmetlerinin kalitesinin arttırılması için geliştirilen akreditasyon ve kalite belgelendirme sistemlerinin süreçlerin belirlenmesinde çalışanların iş sağlığ 1 ve güvenliği ihtiyaçlarının da belirlenip uygun şekilde düzenleme çalışmalarının yapılması toplam kalitenin artırılmasında büyük bir öneme sahiptir. Sağlık hizmeti sunan çalışanların sağlık ve güvenliğinin sağlanması ile etkin, verimli ve güvenli bir şekilde sağlık hizmeti sunumu gerçekleşebilecektir. Bu nedenlerle hastanelerde çalışan güvenliği kültürü oluşturulmalı ve örgüt kültürünün bir parçası haline getirilmeye çalışılmalıdır.

\section{KAYNAKLAR}

1. WHO, 1978, Declaration of Alma-Ata, International Conference on Primary Health Care, Alma-Ata, USSR, 6-12 September http://www.who.int/publications/almaata declaration_en.pdf [ErişimTarihi: 24.12.2017] 
2. Odabaşı Y, Sağlık Hizmetleri Pazarlaması, Anadolu Üniversitesi Yayınları, Eskişehir 2001: 25.

3. US Department of Health and Human Services. National action plan to prevent healthcare-associated infections: roadmap to elimination. http:/www.hhs.gov/ash/initiatives/ hai/hcpflu.html, [Erişim tarihi: 24.12.2017]

4. Saygılı M. Hastane Çalışanlarının Çalışma Ortamlarına İlişkin Algıları İle İş Doyumu Düzeyleri Arasındaki İlişkinin Değerlendirilmesi. Hacettepe Üniversitesi Sağlık Bilimleri Enstitüsü Sağlık Kurumları Yönetimi Programı Yüksek Lisans Tezi, Ankara, 2008.

5. Meydanlıŏlu A, Sağlık Çalışanlarının Sağlığı ve Güvenliği, Health and Safety Of Health Care Workers, Sağlik Bilimleri Dergisi, Balıkesir, Aralık 2013: 2 (3).

6. Devebakan N., Paşalı N. Sağlık İşletmelerinde Hizmet Kalitesi Standartlarının Çalışan Güvenliği Açısından Çalışanlar Tarafindan Değerlendirilmesi: İzmir İlinde Bir Araştırma Hacettepe Sağlik İdaresi Dergisi, 2015: 18(2): 123-142.

7. Sezgin B, Kalite Belgesi Alan Hastanelerde Çalışma Ortamı ve Hemşirelik Uygulamalarının Hasta ve Hemşire Güvenliği Açısından Değerlendirilmesi, İstanbul Üniversitesi Sağlık Bilimleri Enstitüsü, Doktora Tezi, İstanbul, 2007.

8. Bozoğlan H. Acil Serviste Çalışan Güvenliği, Yüksek Lisans Tezi, İstanbul, 2015.

9. Öztürk H, Babacan E, Anahar E.Ö, Hastanede Çalışan Sağlık Personelinin İş Güvenliği, Gümüşhane Üniversitesi Sağlık Bilimleri Dergisi / Gümüşhane University Journal of Health Sciences: 2012: 1(4).

10. Joint Commission International Accreditation Standards For Hospitals, 4th Edition, Effective 1 January, 2011: 193-195.

11. Hasta ve Çalışan Güvenliğinin Sağlanmasına Dair Yönetmelik. Resmi Gazete, 06 Nisan 2011, Say1 27897 http://www.resmigazete.gov.tr/eskiler/2011/04/20110406-3. htm [Erişim tarihi: 08.01.2018]

12. Özkan Ö. Hastanede Çalışan Hemşirelerin İş ve Çalışma Ortamı Tehlike ve Riskleri İle Risk Algılarını Saptanması, Hacettepe Üniversitesi Sağlık Bilimleri Enstitüsü; Ankara, 2005.

13. Akçapınar M., İş Sağlığı ve Güvenliği Kapsamında Kalite Yönetimi Uygulanan Hastanelerin Doğumhanelerinde Çalışan Güvenliği ve Çalışan Güvenliğini Etkileyen Nedenler, T.C. Dokuz Eylül Üniversitesi Sağlık Bilimleri Enstitüsü Sağlıkta Kalite Geliştirme ve Akreditasyon Anabilim Dalı Yüksek Lisans Tezi, İzmir, 2015.

14. Sağlıkta Buluşma Noktası. Hastanelerde Hasta ve Çalışan Güvenliği Ne Boyutlarda? http://www.sbn.gov.tr/icerik. aspx?id=113 [Erişim tarihi: 29.12.2017]

15. Akkaya, G. Avrupa Birliği ve Türk Mevzuatı Açısından Sağlık Kuruluşlarında İş Sağlığı, İş Güvenliği, Meslek Hastalıkları ve Bir Araştırma, Doktora Tezi, İstanbul Üniversitesi, Sosyal Bilimler Enstitüsü, İstanbul, 2007.

16. İnci M, Aksebzeci AT, Yağmur G, Kartal B, Emiroğlu M, Erdem Y. Hastane Çalışanlarında HBV, HCV ve HIV Seropozitifliğinin Araştırılması. Türk Hijyen ve Deneysel Biyoloji Dergisi 2009: 66 (2): 59-66.
17. Reddy S, Manuel R, Sheridan E, Sadler G, Patel S, Riley P. Brucellosis in the UK: a risk to laboratory workers? Recommendations for prevention and management of laboratory exposure. J Clin Pathol 2010: 63: 90-92.

18. Wilburn SQ. Eijkemans G. Preventing needlestick injuries among healthcare workers: A WHO-ICN collaboration. Int J Occup Environ Health 2004: 10: 451-456.

19. Centers for Disease Control and Prevention. Sharp Injury Prevention Program Workbook 2008. https://www.cdc.gov/ sharpssafety/pdf/WorkbookComplete.pdf [Erişim tarihi: 03.01.2018]

20. Yeşildal N. Sağlık Hizmetlerinde İş Kazaları ve Şiddetin Değerlendirilmesi TSK Koruyucu Hekimlik Bülteni, 2005: 4 (5): 280.

21. Bilir N., Yıldız, A N, İş Sağlığı ve Güvenliği, Ankara, Hacettepe Üniversitesi Yayınları, 2004.

22. Fişek G. Sağlık personeli sağlı̆̆1. http://www.sbn.gov.tr/ icerik.aspx?id=116 [Erişim tarihi: 03.01.2018]

23. Caruso C C. Negative Impacts of Shiftwork and Long Work Hours. 2013 Association of Rehabilitation Nurses Rehabilitation Nursing 2014, doi: 10.1002/rnj.107.

24. Önder Ö R, Ağırbaş İ, Yenimahalleli G, Aksoy A. Ankara Numune Eğitim Ve Araştırma Hastanesinde Çalışan Hekim ve Hemşirelerin Geçirdikleri İş Kazaları Ve Meslek Hastalıkları Yönünden Değerlendirilmesi. Ankara Üniversitesi Dikimevi Sağlık Hizmetleri Meslek Yüksekokulu Dergisi, 2011: 10 (1): $31-44$.

25. Altınel L, Köse KÇ, Cihan Altınel E. Profesyonel Hastane Çalışanlarında Bel Ağrısı Prevalansı ve Bel Ağrısını Etkileyen Faktörler. Tıp Araştırmaları Dergisi 2007: 5(3):115-120.

26. Vural F, Fil Ş, Çiftçi S, Dura AA, Yıldırım F, Patan R. Ameliyathanelerde Radyasyon Güvenliği; Çalışan Personelin Bilgi, Tutum Ve Davranışları. Balıkesir Sağlık Bilimleri Dergisi. Aralık 2012: 1 (3).

27. Saygun M. Sağlık Çalışanlarında İş Sağlığı ve Güvenliği Sorunlar1. TAF Prev Med Bull 2012: 11(4): 373-382.

28. Centers for Disease Control and Prevention. National Institute for Occupational Safety and Health. Guidelines for protecting the safety and health of health care workers. https://www.cdc.gov/niosh/docs/88-119/pdfs/88-119.pdf [Erişim Tarihi: 08.01.2018]

29. Annagür B. Sağlık Çalışanlarına Yönelik Şiddet: Risk Faktörleri, Etkileri, Değerlendirilmesi ve Önlenmesi. Psikiyatride Güncel Yaklaşımlar Current Approaches In Psychiatry 2010: 2(2): 161-173.

30. Fernandes C, Bouthillette F, Raboud JM, Bullock L, Moore $\mathrm{C}$, Christenson JM, et al. Violence İn The Emergency Department: A Survey Of Health Care Workers. CMAJ 1999: 16:161-170.

31. Hoşoğlu S., Tanrıkulu A. Ç., Dağlı C. ve Akalın Ş. Bir Üniversite Hastanesinin Çalışanlarında Tüberküloz Riski, Toraks Dergisi, (2004) 5(3): 196-200.

32. Devebakan N, Paşalı N. Sağlık İşletmelerinde Hizmet Kalitesi Standartlarının Çalışan Güvenliği Açısından Çalışanlar Tarafından Değerlendirilmesi: İzmir İlinde Bir Araştırma, Hacettepe Sağlı İdaresi Dergisi, 2015: 18(2): 123-142.

33. http://www.resmigazete.gov.tr [Erişim Tarihi:01.01.2018] 